\title{
ASSESSMENT OF SEISMIC INPUT ENERGY BY MEANS OF NEW DEFINITION AND THE APPLICATION TO EARTHQUAKE RESISTANT DESIGN
}

\author{
Aondowase John Shiwua', Yuri Rutman² \\ 1,2Saint Petersburg State University of Architecture and Civil Engineering, \\ Vtoraja Krasnoamieskaja ul. 4, 190005, St. Petersburg, Russia \\ 19aondo.j@gmail.com, ${ }^{2605 f r a c t a l @ m a i l . r u ~}$
}

\begin{abstract}
A methodology for assessing the seismic input energy into structure (building) from earthquake (or seismic) excitation is proposed. The procedure is based on the energy balance of the structure and employs the earthquake intensity characteristic known as the specific energy density (SED) to estimate the maximum input energy. This energy is evaluated for the portion of earthquake record (accelerogram) where strong ground motion occurs (the interval between $5-95 \%$ accumulations of the Arias intensity). Comparison of the proposed approach in this paper and other proposals for assessing seismic input energy as a basis for energy-based seismic design methodology is presented. Since a critical condition to realize an energy-based seismic design is that the structure should have a rational relationship between damage/energy absorbed, the procedure establishes a relation between the seismic input energy into structure and strain, total cyclic displacement and low cycle fatigue. Seismic input energy obtained using this procedure is compared with results from other methods for assessment of seismic input energy. The procedure can useful especially, at the initial stage of design to provide the desired ductility to structure since it allows for evaluating the maximum input energy into structural system from any seismic excitation without recourse to dynamic analysis.
\end{abstract}

\section{Keywords}

Energy-based method, displacement, low-cycle fatigue, seismic excitations, seismic input energy, strain

\section{Introduction}

In most cases, seismic design practices structures are based on representing the earthquake loading effect in terms of static equivalent forces that are calculated from elastic response spectra relating the peak ground acceleration ( $P G A)$ with the absolute pseudo-acceleration response implemented in several current seismic codes. This procedure indirectly attempts to account for inelastic behavior during severe seismic excitation and the overstrength of the structure through ductility-based force-reduction factor, $R$. Based on these understanding, Fajfar (1992), proposed a methodology in which the ductility of the structure is reduced by a non-dimensional parameter $\gamma$ that represents a normalization of the dissipated hysteretic energy $E_{\mathrm{H}}$. Teran-Gilmore and Jirsa, (2005) used the observed correlation between the plastic energy demand $E_{\mathrm{H}}$ and the strength reduction factor $R$ to propose two procedures for seismic design against low-cycle fatigue.
The force-based method has a number of disadvantages, which are outlined by Priestley et al. (2007). One of such disadvantages is that the earthquake loading effect depends on the elastic and plastic characteristics of the structure, which in turn govern the structural resistance. This relationship between earthquake loading effect and structural resistance makes seismic design cumbersome. In addition, the concept of equivalent ductility allows only implicitly to address the cumulative damage (low cycle fatigue) and is dependent on series of empirical parameters. Furthermore, the degree of protection against damage provided by force-based design methods under a given seismic intensity is non-uniform from structure to structure.

Since the 1990s, more emphasis has been laid on displacement considerations, resulting in the development of displacement-based design methods (Priestley et al., 2007). The maximum relative displacement is the structural response index 
often used for evaluating the inelastic behaviour of structures. However, it is widely recognized that apart from maximum displacement, the level of structural damage from seismic excitation depends on the cumulative damage resulting from numerous inelastic cycles (Fajfar and Vidic, 1994).

Recent earthquake excitations such as 2005 Kashmir earthquake in India, 2008 Sichuan earthquake in China, 2011 Fukushima earthquake in Japan and most recently the Central Italy earthquake of 2016 have imposed severe damage to relatively new buildings (structures) across several cities, designed based of some force- or displacementbased methods. These damages may in part be due to construction and design errors, and or partly due to the shortcomings of the employed seismic design method (code). If the latter is the case, it is a further confirmation that force-based design and displacement-based design does not result in reliable structural seismic design of building systems.

Serious consideration of seismic energy as an alternative index to other response quantities such as force or displacement earthquake resistant design began in 1950s. Since the original works by Housner (1956), Berg and Thomaides (1960), Kato and Akiyama (1975) and Housner and Jennings (1977), the energy-based procedure has been widely developed Zahrah and Hall (1984), Akiyama (1985), Kuwamura and Galambos (1989), Unag and Bertero (1990), Fajfar et al. (1992), McCabe and Hall (1989), Zhu and Tso (1992). Anderson and Bertero (2006) have given a review on the evolution of the energy-based method.

The fundamental basis of the energy-based seismic design (EBSD) is that, unlike the force-based and displacement-based methods of earthquake resistant design, is that the loading effect of seismic excitation on structures can be interpreted not as forces or displacements separately, but rather as the product of both, in terms of input energy $E_{\mathrm{I}}$. A design approach based on energy, has the potential to address the effects of the duration, frequency content and hysteretic behaviour directly Khashaee et al. (2003). It must be noted, however, that the loading history also affects cumulative damage as discussed by several authors some of which include Benavent_Climent (2007); Chai (1995, 2004), Erberik and Sucouglu (2004), Sucouglu and Erberik (2004) in the context of both steel and reinforced concrete structural elements.

A basic parameter for the implementation of energy-based concepts is the estimation of the input energy that is considered a reliable indicator of ground motion severity. Accurate estimation of the seismic input energy from seismic excitation is therefore, very important. Researchers have used different earthquake strong-motion parameters for characterization of seismic hazard Safac (2000),
Chou and Uang (2000), Ambraseys and Douglas (2003), Decanini and Mollaoli (1998, 2001), Benavent-Climent et al. (2002), Teran-Gilmore and Jirsa (2007), Amiri et al. (2008), Shiwua (2014), Rutman and Shiwua (2015). This has resulted in the proposal of strong-motion attenuation relationships, design energy input spectra and various formulations for representing the seismic demand with reference to single-degree-of-freedom (SDOF) systems.

In an energy-based seismic design, one needs to estimate the input energy in a structure and distribute it to various structural components. The development of an effective and feasible procedure for analyzing and evaluating the seismic demands is one major challenge in energy-based seismic design of structures. This paper seeks to offer an alternative procedure for assessing the seismic input energy into structural system based on energy considerations. The proposal employs the earthquake intensity characteristic known as the specific energy density (SED) to estimate the maximum input energy and establishes a relation between the seismic input energy into structure and strain, total cyclic displacement and low cycle fatigue.

\section{Materials and method}

The materials and methods used include proven research work by authors on the subject of energybased seismic design, theory of seismic stability, general assumptions of structural mechanics, theory of elasticity and plasticity, earthquake records in the form of accelerogram and computer software like Nonlin, SeismoSignal and Ing+.

\section{Existing procedures for computing input energy}

Several methods have being proposed for estimating seismic input energy. However, only a select few will be examined for comparison within the context and limitations of this work.

Housner (1956) has presented a first estimation of the input energy per unit mass, based on the maximum kinetic energy, for both elastic and inelastic behaviour as:

$$
E_{\mathrm{I}} / m=1 / 2(P S V)^{2}
$$

where $m$ is the mass and $P S V$ denotes the pseudospectral velocity.

Akiyama (1985) proposed the input energy per unit mass for an elastic SDOF structure as:

$$
E_{\mathrm{I}} / m=1 / 2\left(V_{\mathrm{E}}\right)^{2}
$$

where $V_{E}$ (in $\mathrm{m} / \mathrm{s}$ ) is an equivalent velocity. He recommended the following values for $V_{E}$

$$
V_{\mathrm{E}}=2.5 T \text { for } T \leq T_{\mathrm{G}} ; V_{\mathrm{E}}=2.5 T_{\mathrm{G}} \text { for } T \geq T_{\mathrm{G}}
$$

where $T$ is the period of the system, $T_{G}$ is the predominant period of ground motion as a function of soil type. The values of $T_{\mathrm{G}}$ are $0.4,0.6,0.8$, and $1.0 \mathrm{~s}$ for soil types I (bedrock), II, III, and IV (softest soil), respectively. 
Kuwamura and Galambos (1989) used the equation proposed by Akiyama and recommended the following values for $V_{E}$

$$
\begin{gathered}
E_{\mathrm{I}} / m=1 / 2\left(V_{\mathrm{E}}\right)^{2} \\
V_{E}=0.5 \sqrt{I_{\mathrm{E}} T_{\mathrm{G}}} \text { for } T \geq T_{G} ; \\
V_{E}=0.5 \sqrt{I_{\mathrm{E}} / T_{\mathrm{G}}} T \text { for } T \leq T_{G}
\end{gathered}
$$

where $I_{\mathrm{E}}=\int_{0}^{t} \ddot{u}_{g}^{2} d t$ is the integral of the square of the ground acceleration for the total duration of accelerogram $t$.

Uang and Bertero (1990), proposed two different approaches to estimate the input energy, based on either the absolute or the relative equation of motion. Chopra (1995), and Bruneau and Wang (1996) believe that the input energy in terms of the relative motion is more meaningful than the input energy in terms of the absolute motion since internal forces within a structure are computed using relative displacements and velocities. The relative input energy per unit mass is defined as:

$$
E_{\mathrm{I}} / m=-\int_{0}^{t} \ddot{u}_{g} \dot{u} d t
$$

where $\dot{u}$ is the velocity of the mass relative to ground and $\ddot{u}_{g}$ is the ground acceleration.

Rutman (2012) proposed a formula that establishes the relation between the possible maximum seismic energy received by the system, and the criterion of cumulative absolute velocity (CAV). The proposal is generalised and does not depend on the degrees of freedom of a system, and on the presence of nonlinearities. This estimate is given as:

$$
E(t)_{\mathrm{B}} \leq 1 / 2 m(C A V)^{2}
$$

where $E(t)_{\mathrm{B}}$ the seismic input energy into a system, $C A V=\int_{0}^{t}|\ddot{X}(\xi)| d \xi$ is the cumulative absolute velocity, $\ddot{X}$ is the ground acceleration.

Shiwua (2014) has applied Arias intensity to assess the seismic energy. The evaluation of the input energy per unit mass, taking into account only the nature of the impact is expressed as:

$$
E_{I} / m=1 / 2\left(I_{\mathrm{A}}\right)^{2}
$$

where $I_{A}=\pi / 2 g \int_{0}^{t} \ddot{u}_{g}^{2}(t) d t$ is Arias intensity.

\section{Background on energy-balance equation}

The equation of motion of an inelastic singledegree-of-freedom system (SDOF) subjected to a unidirectional horizontal ground motion can be written as follows:

$$
m \ddot{u}+c \dot{u}+F(u, \dot{u})=-m \ddot{u}_{g}
$$

where $m$ is the mass, $c$ is the damping coefficient, $F(u)$ is the restoring force, $u$ is the relative displacement of mass, $\dot{u}$ is velocity of mass relative to base (first derivative with respect to time), $\ddot{u}$ is the acceleration of mass relative to base (or second derivatives with respect to time), $\ddot{u}_{g}$ is the ground acceleration.
Dividing all terms by the mass $m$, the Eq. (8) can be written in the form:

$$
\ddot{u}+2 \xi \omega \dot{u}+f(u, \dot{u})=-\ddot{u}_{g}
$$

where $\xi=c / 2 \omega m$ is the dimensionless damping ratio, $\omega$ is natural frequency of the system, $f(u, \dot{u})$ is the restoring force per unit mass.

Multiplying (8) by $d u=\dot{u} d t$ and integrating over the entire duration of the earthquake give the energy balance equation

$$
E_{\mathrm{K}}+E_{\xi}+E_{\mathrm{A}}=E_{\mathrm{I}}
$$

where $E_{\mathrm{K}}=\int_{0}^{t} \dot{u} m \ddot{u} d t=\frac{1}{2} m \dot{u}^{2}$ is the relative kinetic energy, $E_{\xi}=\int_{0}^{t} c \dot{u}^{2} d t$ is damping energy, $E_{A}=\int_{0}^{t} F(u, \dot{u}) \dot{u} d t$ is the absorbed energy and $E_{\mathrm{I}}=-\int_{0}^{t} m \ddot{u}_{g} \dot{u} d t$ is the relative input energy. The absorbed energy comprises of the recoverable elastic strain energy, $E_{\mathrm{S}}$, and the energy dissipated through plastic deformation (irrecoverable hysteretic energy), $E_{\mathrm{H}}$, that represents the cumulative damage to the structure, i.e. $E_{\mathrm{A}}=E_{\mathrm{S}}+E_{\mathrm{H}}$ and Eq. (10) is rewritten as:

$$
E_{\mathrm{K}}+E_{\xi}+E_{\mathrm{S}}+E_{\mathrm{H}}=E_{\mathrm{I}}
$$

The left-hand side of equation (11) describes the ultimate energy absorbing capacity (UEAC) while the right-hand side of the equation represents the loading in terms of input energy into a structure from earthquake excitation. Seismic stability of the structure can be evaluated by comparing the expected value $E_{\mathrm{I}}$ at the site where the structure is located, with the value of UEAC (Benevant-Clement and Zahran, 2010). At the brink of collapse, the UEAC and $E_{\mathrm{I}}$ have the same value; therefore the seismic capacity of building can be expressed in terms of the $E_{\mathrm{I}}$ corresponding to the "ultimate earthquake" that the building can resist.

On the other hand, the sum of $E_{\mathrm{K}}$ and $E_{\mathrm{S}}$ constitutes the elastic vibrational energy of the system, $E_{\mathrm{E}}$. So that equation (11) can be rewritten as:

$$
E_{\mathrm{E}}+E_{\mathrm{H}}=E_{\mathrm{I}}-E_{\xi}
$$

The difference between $E_{\mathrm{I}}$ and $E_{\xi}$ is considered the energy input that contributes to damage $E_{\mathrm{D}}$ by Housner (1956).

$$
E_{\mathrm{D}}=E_{\mathrm{I}}-E_{\xi}
$$

At the end of the ground motion duration $E_{\mathrm{E}}$ is almost zero; consequently, from Eqs. (12) and (13) it follows that $E_{\mathrm{H}}$ can be taken as equal to $E_{\mathrm{D}}$, i.e. $E_{\mathrm{H}} \approx E_{\mathrm{D}}$. Further, $E_{\mathrm{I}}$ and $E_{\mathrm{D}}$ can be normalized by the mass $\mathrm{m}$ and expressed in terms of equivalent velocities $V_{\mathrm{E}}$ and $V_{\mathrm{D}}$ defined by:

$$
V_{\mathrm{E}}=\sqrt{2 E_{\mathrm{I}} / m} ; V_{\mathrm{D}}=\sqrt{2 E_{\mathrm{D}} / m}
$$

Numerical analysis of the inelastic response under earthquakes shows that the seismic input energy, $E_{\mathrm{I}}$, is mildly affected by the strength; is insignificantly affected by the configuration of the 
restoring force characteristics of the structure and scarcely affected by the fraction of critical damping $\xi$. The ratio, $E_{\mathrm{I}} / m$, is independent of the total mass $m$ of the structure and mainly dependent on the vibration periods $T_{i}$ of the structure, mostly on that of the first mode $T_{1}$ (Zahrah and Hall,1984; Akiyama, 1985; and Kuwamura and Galambos, 1989).

Procedure for estimation of seismic input energy into SDOF system during earthquake

When the structure enters the inelastic range, there is a deterioration of the hysteretic behaviour, which can lead to failure of critical elements at deformation levels significantly below the ultimate deformation capacity of the structure. Therefore, of particular interest is the dissipated hysteretic energy, $E_{\mathrm{H}}$, which is the structural response parameter that is commonly correlated to cumulative damage, and it provides a good characterization of the severity of plastic cycling (Teran-Gilmore and Jirsa, 2005). Due to the monotonicity of $E_{\mathrm{H}}$, the evaluation, of its maximum value must be done at the end of seismic excitation or at the end of the intensive phase of excitation $(\bar{t})$.

Numerical analysis shows that the term $E_{\xi}=\int_{0}^{t} c \dot{u}^{2} d t$ in Eqs.(10) - (12) for a SDOF system (Fig. 1) can be neglected due to its smallness. Integrating $\int_{0}^{t} \ddot{u}_{g} \dot{u} d t$ by parts results to the following expression:

$$
E_{\mathrm{I}, 1}=\int_{0}^{\bar{t}} \ddot{u}_{g} \dot{u} d t=\left.\dot{u}_{g} \dot{u}\right|_{0} ^{\bar{t}}-\int_{0}^{\bar{t}} \dot{u}_{g} \ddot{u} d t=-\int_{0}^{\bar{t}} \dot{u}_{g} \ddot{u} d t
$$

where $E_{\mathrm{I}, 1}$ is input energy per unit mass.

By neglecting viscous damping from Eq. (8) or (9), it follows that

$$
\ddot{u}=-f(u, \dot{u})-\ddot{u}_{g}
$$

By substituting Eq. (16) into (15), we obtain:

$$
\begin{aligned}
& E_{\mathrm{I}, 1}=\int_{0}^{\bar{t}} \ddot{u}_{g} \dot{u} d t=\int_{0}^{\bar{t}} \dot{u}_{g}\left(f(u, \dot{u})+\ddot{u}_{g}(t)\right) d t= \\
& \quad=\int_{0}^{\bar{t}} \ddot{u}_{g} \dot{u}_{g} d t+\int_{0}^{\bar{t}} f(u, \dot{u}) \dot{u}_{g} d t \\
& =\left.\frac{\dot{u}_{g}{ }^{2}}{2}\right|_{0} ^{\bar{t}}+\int_{0}^{\bar{t}} \dot{u}_{g} f(u, \dot{u}) d t=\int_{0}^{\bar{t}} \dot{u}_{g} f(u, \dot{u}) d t
\end{aligned}
$$

At the end of the ground motion duration $E_{\mathrm{E}}$ is almost zero; consequently, from Eqs. (12) and (13) it follows that $E_{\mathrm{H}}$ can be taken as equal to $E_{\mathrm{D}}$, i.e. $E_{\mathrm{H}} \approx E_{\mathrm{D}}$. Given that $\dot{u}_{g}(\bar{t})=0$ and taking into account Eq. (17), we obtain the following expression from (12)

$$
E_{\mathrm{H}, 1} \leq \int_{0}^{\bar{t}}\left|\ddot{u}_{g} \dot{u}\right| d t=\int_{0}^{\bar{t}}\left|\dot{u}_{g} f(u, \dot{u})\right| d t
$$

where $E_{\mathrm{H}, 1}$ is hysteretic energy per unit mass.

Let us introduce the following notation

$$
|f(u, \dot{u})|=f_{\max }
$$

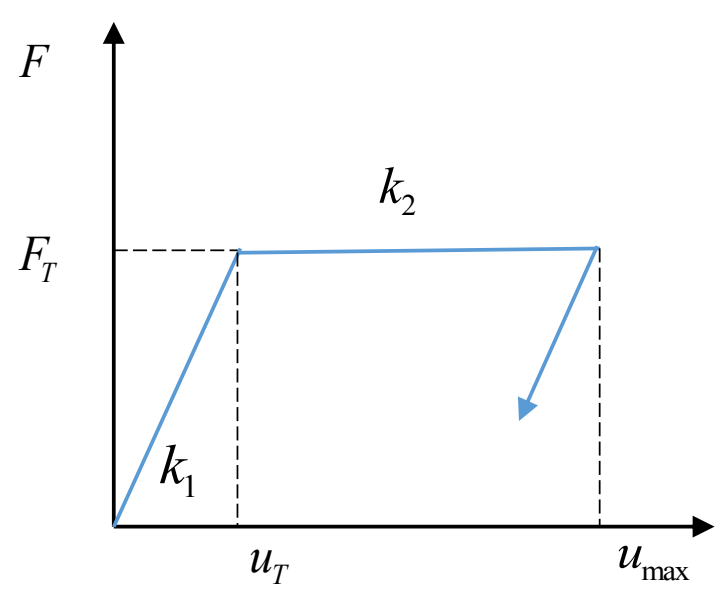

Figure 1. Elastic perfectly plastic (Elastoplastic) system

Using Eqs. (18) and (19) and applying the Cauchy-Schwarz inequality we obtain:

$$
E_{\mathrm{H}, 1} \leq f_{\max } \sqrt{\bar{t} \int_{0}^{\bar{t}} \dot{u}_{g}^{2} d t}
$$

where $f_{\max }$ is the lateral yield force, $\bar{t}$ in the time corresponding to the duration of strong ground motion (Fig. 2). The integral $\int_{0}^{t} \dot{u}_{g}^{2} d t$ is referred to as the Specific Energy Density of earthquake. In this case, the SED value is determined for an interval of the duration of earthquake motion $\bar{t}$ corresponding to the significant duration and defined as $\int_{0}^{t} \dot{u}_{g}^{2} d t$.

Equation (20) can be expressed as:

$$
E_{\mathrm{H}, 1} \leq f_{\max } \sqrt{\overline{t S E D}}=E_{\mathrm{SED}}
$$

where $E_{\mathrm{SED}}$ is the seismic input energy per unit mass based on SED.

Transition from energy loading of system to level of deformation during elastoplastic cyclic loading

A relationship between the input energy demand and the maximum displacement of structure

The diagram shown in Figure 3 schematically represents typical shear drift curve, $f-\Delta$, of a given SDOF system (building) subjected to seismic actions.

The values $|f(u, \dot{u})|$ and $\Delta_{i}$ are the corresponding values at yielding. The integration of the $f-\Delta$ curve i.e. linear summation of the displacements at different stages of cyclic deformation, gives the hysteretic energy dissipated by the system, $E_{\mathrm{H}}$, which represents the cumulative damage in that storey (or building).

Following the notation in Figure 3, we obtain:

$$
E_{\mathrm{H}, 1}=f_{\max } \sum_{i=1}^{z}\left|\Delta_{i}\right|
$$

where $\Delta_{i}$ is cyclic displacement corresponding $i$-th cycle, $z$ is the number of half cycles. 


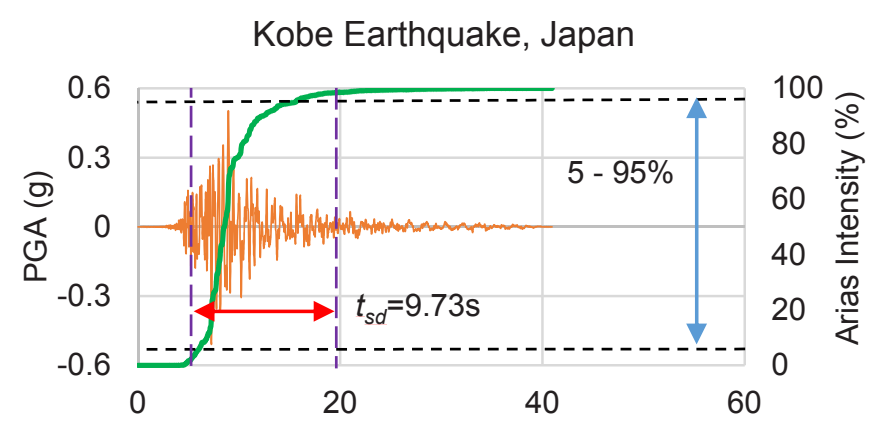

$\mathrm{t}(\mathrm{s})$

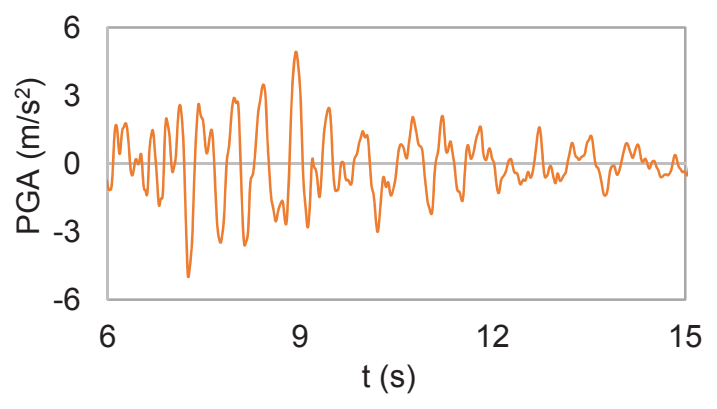

$\mathrm{t}(\mathrm{s})$

Figure 2. Interval of the strong motion on the example of Kobe earthquake record, Japan

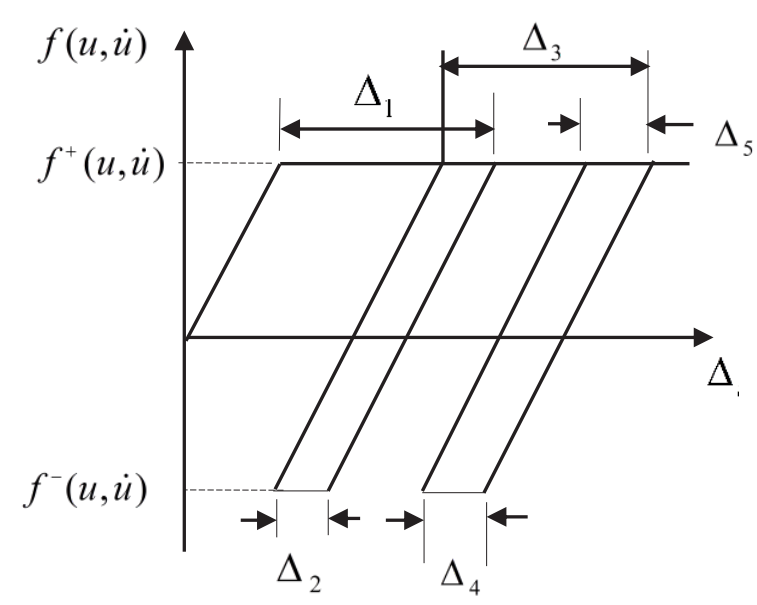

Figure 3. Cyclic stress-strain diagram

From equations (21) and (22) we obtain:

$$
f_{\max } \sum_{i=1}^{z}\left|\Delta_{i}\right| \leq f_{\max } \sqrt{\bar{t} S E D}
$$

This way is the total displacement of the system with single degree of freedom is expressed as:

$$
\sum_{i=1}^{z}\left|\Delta_{i}\right| \leq \sqrt{\bar{t} S E D}
$$

The left hand side of the inequality (24) is considered (within the framework of the above assumptions of using a model with single degree of freedom) as the total cyclic displacement of the top of the structure. If a relationship between displacement and deformation is established, the relation (24) allows determining the possibility of low-cycle fracture.

\section{Relationship between deformation and displacement}

Usually, in order to simplify analysis beyond the elastic limit, strain (deformation) curves are schematized. A common variant of this schematization is the stress-strain exponential relationship given as:

$$
\sigma=\bar{B}_{1}|\varepsilon|^{\mu-1} \varepsilon
$$

where $\sigma$ - stress, $\varepsilon-$ strain, $\bar{B}_{1}$ characteristic parameter for the considered material, $\mu$ is strain hardening parameter, $\bar{B}_{1}>0$ and $\mu \leq 1$ are constants.

Applying the stress-strain exponential relationship leads to following relation:

$$
\bar{B}_{1} J_{\mathrm{ob}}|\chi|^{\mu-1} \chi=-M
$$

where $\chi=d^{2} v / d x^{2}$ is the curvature of the beam, $J_{\mathrm{ob}}$ is the generalized moment of inertia.

Figure 4 shows the stress dependence on the index $\eta$ due to beam bending. Plastic deflection for a cantilever shown in Figure 5 (Simbort, 2012) is defined as follows:

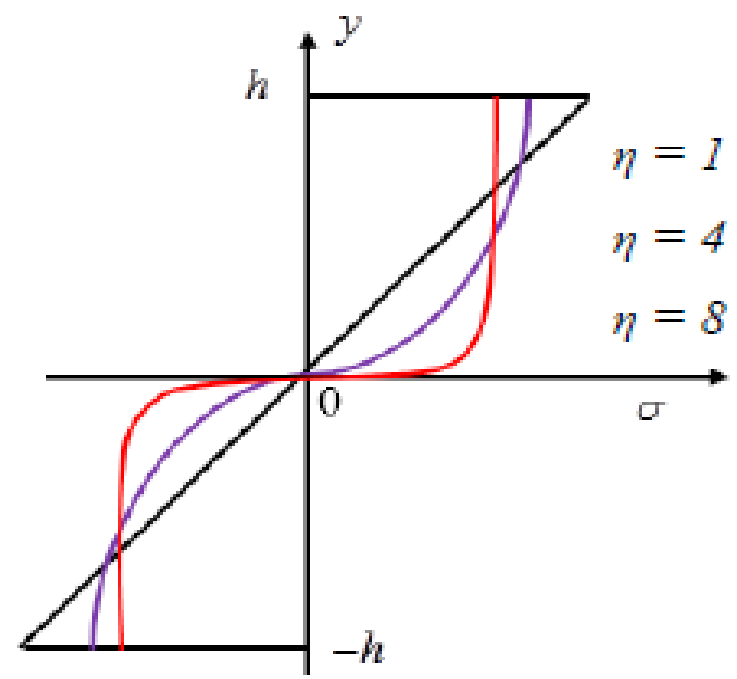

Figure 4. Relationshinp between the parameter $\eta$ and stress distribution under bending

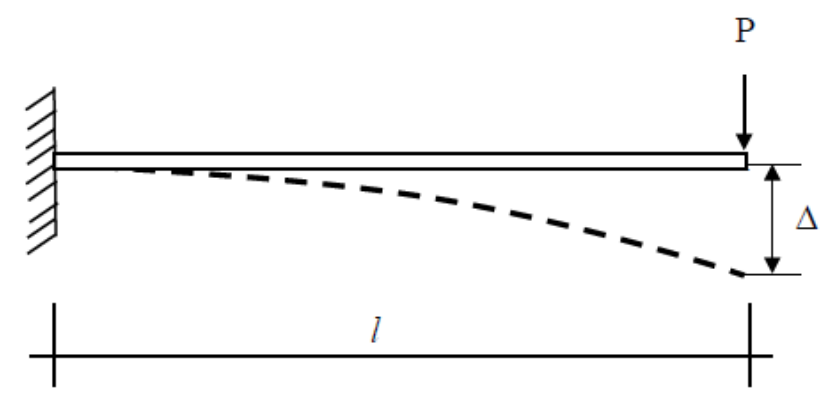

Figure 5. Deflection of cantilever beam 


$$
\Delta=\frac{P^{\eta} l^{2+\eta}}{(2+\eta) D}
$$

where $\eta=1 / \mu, D=\bar{B}_{1}^{\eta} J_{\mathrm{ob}}^{\eta}, P$ point load at the end of the beam, and $I$ is the length of the beam.

Applying the recommendations of Simbort (2012) to Eqs. (26) and (27) result in the following relationship between deformation (strain) and displacement

$$
\begin{aligned}
\Delta= & \frac{M^{\eta} l^{2}}{(2+\eta) D}=\frac{\left[\bar{B}_{1} J_{\mathrm{ob}}\left(\frac{\varepsilon}{h}\right)^{\mu}\right]^{\eta} l^{2}}{(2+\eta) D}= \\
= & \frac{\bar{B}_{1}^{\eta} J_{\mathrm{ob}}^{\eta} \frac{\varepsilon}{h} l^{2}}{(2+\eta) \bar{B}_{1}^{\eta} J_{\mathrm{ob}}^{\eta}}=\frac{\varepsilon l^{2}}{h(2+\eta)}
\end{aligned}
$$

By making the strain in Eq. (28) the subject of the formula, we obtain

$$
\varepsilon=\frac{h(\Delta)}{l^{2}}(\eta+2)
$$

where $h$ is height of beam section.

Figure 6 is used to describe one of the possible ways of establishing a relationship between top displacement of structure and the maximum deformation. Often, in framed buildings structures, the weakest is the lower (first) storey. The lower storey is weakened for functional reasons: the presence of many shops, public facilities and open spaces, etc., so there are less load-bearing columns. At the same time, the maximum load acts on the lower floor (storey). During transition to limit equilibrium state, plastic hinges are formed only at the lower storey. Therefore, the displacement of the top of the building coincides with the displacement of the ground floor beam.

In this case, considering the bending moment diagram of columns, the bending moment at the middle is equal to zero. The column behaves as two identical, sequentially, connected beams, with plastic hinges at the rigid supports. Based on the above assumption, a transition to the problem of determining the maximum stresses in the elastoplastic cantilever beam with free end displacement is achieved. As shown in Figure 6b, the displacement of the free end of the equivalent cantilever beam is equal to half the displacement of the lower (first) storey beam (floor) and consequently, the top of the building.

The resulting Eq. (29) for cantilever beam can be used to determine the maximum plastic deformations in the structural elements, in particular, in frame elements of buildings.

By following the recommendations of Simbort (2012), it is possible to determine the position plastic hinges (Figure 6a) due to limit load and reduce (or convert) the analysis to the design of cantilever beams.

To achieve this it necessary to

I. Geometrically, link the top displacement of the structure (established upon evaluation of the input seismic energy) to the floor drift of each storey (frame contour).

II. Transit from the floor displacement of each storey to displacement of an equivalent cantilever beam as shown in Figure $6 b$ (at the middle of the column, moment is zero, so its half behaves like a cantilever beam).

III. Use Eq. (29) to determine the maximum deformation in the lower rigid supports of the frame where plastic hinges are formed.

The location of plastic hinges can be determined, by performing limit equilibrium analysis where the horizontal load is proportional to the distributed mass of the system by method of pseudo-rigidity proposed by Routman (1997), and realized in the computer program "Ing+".
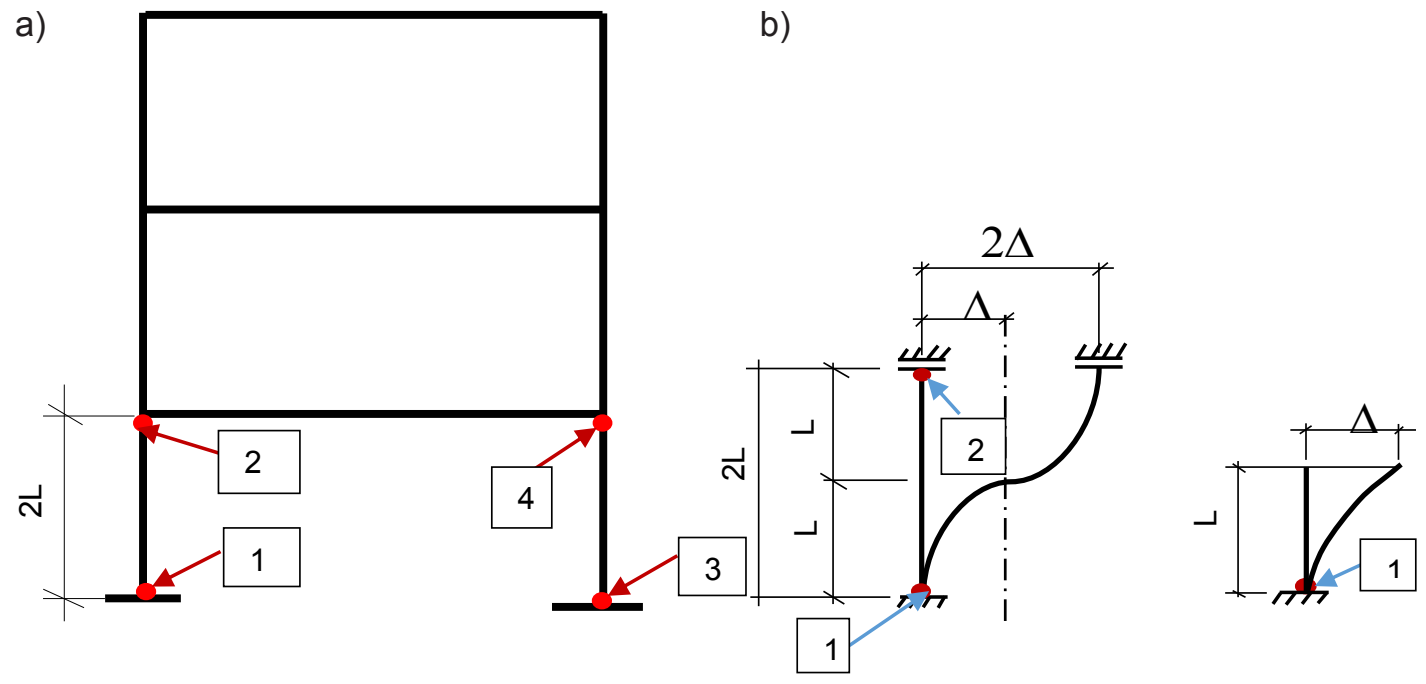

Figure 6. Transition from frame to equivalent cantilever beam:

a) Location of plastic hinges, and b) schematization of equivalent cantilever beam 
The desired ductility (plastic properties) of structures are then optimized, to withstand a given earthquake excitation.

\section{Relationship between deformation and displacement under cyclic loading}

The level of damage to structures due to seismic influence depends not only on the maximum response in terms of forces or lateral displacement. Inelastic excursions below the maximum lateral displacement capacity of the structure can still cause significant damage (low-cycle-fatigue). This duration-related cumulative damage from multiple cycles of elasticplastic deformation has to be accounted for during seismic action on structures. For cyclic deformation with different amplitude, it is convenient to use Martin low-cycle-fatigue criteria based on the CoffinManson's criteria:

$$
\sum_{i=1}^{Z} \Delta \varepsilon_{i}^{2} \leq \varepsilon_{B}^{2} \text { or } 2 \sum_{i=1}^{Z} \Delta \varepsilon_{i}^{2} \leq \varepsilon_{B}^{2}
$$

where $\varepsilon_{B}$ tensile deformation, $Z$ is the number of half cycles, $Z$ is the number of cyclic loading.

If all cycles are the same, then

$$
Z \Delta \varepsilon_{i}^{2} \leq \frac{1}{2} \varepsilon_{B}{ }^{2} \Rightarrow Z^{\frac{1}{2}} \Delta \varepsilon_{i} \leq \frac{\varepsilon_{B}}{\sqrt{2}}
$$

The least or non-damage conditions for a system (structure) under elastoplastic cyclic loading, from seismic excitation can be obtained by relating expressions (30) with (31) as follows

$$
\sum_{i=1}^{z} \Delta \varepsilon_{i}{ }^{2} \leq\left[\sum_{i=1}^{z}\left|\Delta \varepsilon_{i}\right|\right]^{2} \leq \varepsilon_{B}^{2}
$$

From (32) we obtain the following equilibrium condition of stability:

$$
\sum_{i=1}^{z}\left|\Delta \varepsilon_{i}\right| \leq \varepsilon_{B}
$$

Applying the criteria in (33) to the abovementioned method for equivalent cantilever beams (29) and expression (24), we obtain:

$$
\begin{gathered}
\left|\varepsilon_{i}\right|=\frac{h \Delta_{i}}{l^{2}}(\eta+2) \\
\sum_{i=1}^{z} \frac{h \Delta_{i}}{l^{2}}(\eta+2) \leq \frac{h}{l^{2}}(\eta+2) \sqrt{\bar{t} S E D} \leq \varepsilon_{B}
\end{gathered}
$$

The expression (35) can be adopted as a criteria for seismic resistance (stability), based on an assessment of the input energy under elastoplastic loading of a structure during an earthquake.
It should be noted that the proposed assessment is correct only for the design schematic shown in Figure 6, i.e., for plane frame system. In this case, having performed limit equilibrium analysis the top displacement of the frame is geometrically, linked to displacement of an equivalent cantilever beam. As a consequence of such geometric transformation, equation (35) is applied which does not include the value of $f_{\max }$. However, the distribution of energy between the structural elements may be different. Among others, a certain relationship defining the distribution of input seismic energy among individual structural elements. In this case, $f_{\max }$ will be used during the stress-strain state analysis of load-bearing structural members.

\section{Analysis and discussion of results Comparative analysis seismic input energy}

A non-linear analysis was performed in Nonlin for an elastoplastic SDOF system (Figure 1) described by the differential Eq. (9), from seismic excitation. The assessment is carried out for a unit mass system with $0 \%$ damping to estimate the real input energy into moderate systems with periods within the range of $0.02-2.0 \mathrm{~s}(f=0.5-50 \mathrm{~Hz})$, from 4 earthquakes excitations imposed in the form of accelerograms (Table 1). PGA is peak ground acceleration, PGV is peak ground velocity, SED specific energy density, $t_{\mathrm{td}}$ is the total duration and $t_{\mathrm{sd}}$ is significant duration.

The maximum yield (ultimate) load was defined as $f_{\max }=P G A$, where $P G A$ is peak ground acceleration. The total duration of each excitation is taken as interval between 5 and $95 \%$ accumulation of Arias intensity (significant duration) Trifunac and Brady (1975) that characterizes the duration of strong motion.

The predominant period of the ground $\left(T_{\mathrm{G}}\right)$ is determined based on the soil type. These values are taken as 0.4, 0.6, 0.8 and 1s for soil type I, II, III and IV respectively (Khashaee et al., 2003). Values of PSV, CAV, I $I_{A}$ and SED for specified impacts are determined in the SeismoSignal and seismic input energy estimates based on assessments in Eqs. (1), (2), (4), (7) and (21) are also evaluated and the results compared (Figure 7 ).

The results obtained shows that values of the input energy vary significantly, depending on the proposed method, which is explained by the use of different parameters and assumptions. In some

Table 1

Earthquake records

\begin{tabular}{|l|l|l|l|l|l|l|l|}
\hline Earthquake name & Country and date & \multicolumn{1}{|c|}{ Component } & PGA $\left(\mathrm{m} / \mathrm{s}^{2}\right)$ & $\begin{array}{l}\text { PGV } \\
(\mathrm{m} / \mathrm{s})\end{array}$ & \multicolumn{1}{|c|}{ SED } & $t_{\text {td }}(\mathrm{s})$ & \multicolumn{1}{c|}{$t_{\text {sd }}(\mathrm{s})$} \\
\hline Kobe & Japan, 1995 & $0^{\circ}$ & 4.99 & 0.36 & 0.164 & 40,95 & 9.73 \\
\hline Avej & Iran, 2002 & Long & 4,37 & 0.25 & 0.028 & 58,86 & 6 \\
\hline Loma Prieta & 1989 & $270^{\circ}$ & 2,7 & 0.37 & 0.108 & 40 & 7,8 \\
\hline Parkfield & 1971 & $40^{\circ}$ & 2.33 & 0.11 & 0.026 & 26.2 & 13,8 \\
\hline
\end{tabular}


cases, the obtained values of maximum seismic energy are underestimated compared to the real values from equation (9). Consequently, it can result to underestimation of the desired ductility (plastic properties) which in turn govern the structural resistance, should be based the accurate assessment of the input energy into the structure (or system). It is important to note that the proposed assessment (21) always give seismic input energy value above the real values, thereby excluding any possibility of inadequate ductility during energybased design.

Determination cyclic deformation in a SDOF multi-storey plane frame

To determine the cyclic deformation in multi-storey plane frame SDOF system (Figure 7), the following parameters and seismic excitations (Table 2) were used

$$
\begin{gathered}
h=0.4 \mathrm{~m}, l=3.5 \mathrm{~m}, \eta=5, \varepsilon_{B}=0.2, \\
\sqrt{\tilde{t} S E D}=E_{S E D} / f_{\max }, f_{\max }=\lambda P G A, \lambda=0.25
\end{gathered}
$$

where $I$ is length of equivalent cantilever beam, $\mathrm{h}$ is section height of beam, $\eta$ is bending parameter, $\varepsilon_{B}$ is permissible deformation limit, $\lambda$ is yield force reduction factor.

The results (Table 3 ), indicate that for seismic excitations 2-10, the deformation in the system are within acceptable limits. However, for the first excitation, the deformation exceeds the permissible value. This means that to ensure the seismic resistance of the system, it is necessary to make corrections to initial design data.

\section{Conclusions}

This work has shown that the value of the seismic input energy into system from seismic excitation differ, significantly, depending on the method used. It is important at the initial design stage not to underestimate the input energy, as it will undermine the provision of desired ductility, which in turn governs the seismic resistance.

The procedure proposed always evaluates the seismic input energy above the real values with

Table 2

Characteristics of earthquake records

\begin{tabular}{|c|l|l|l|l|}
\hline No. & Earthquake & PGA $\left(\mathrm{m} / \mathrm{s}^{2}\right)$ & SED $\left(\mathrm{m}^{2} / \mathrm{s}\right)$ & $\begin{array}{l}\text { Duration, } \\
t(\mathrm{~s})\end{array}$ \\
\hline 1 & Chi-chi & 4.32 & 2.442 & 26.49 \\
\hline 2 & Friuli & 3.43 & 0.025 & 4.24 \\
\hline 3 & Kobe & 5.00 & 0.164 & 9.73 \\
\hline 4 & Kacaeli & 3.51 & 0.314 & 10.56 \\
\hline 5 & Northridge & 9.15 & 0.388 & 8.53 \\
\hline 6 & Ano Liosia_K & 3.01 & 0.007 & 4.41 \\
\hline 7 & Ano Liosia_S & 2.38 & 0.006 & 3.86 \\
\hline 8 & Avej & 4.37 & 0.024 & 6 \\
\hline 9 & Kozani & 2.04 & 0.005 & 6.46 \\
\hline 10 & Montenegro & 2.62 & 0.020 & 9.95 \\
\hline
\end{tabular}

reasonable margin of safety, which excludes the possibility of underestimating the desired ductility. This procedure is performed without recourse to dynamic analysis and is a convenient tool for selection of key design parameters at the initial design stage.

Based on the definition of seismic input energy proposed, a relationship is established between deformation and total cyclic displacement, and low cycle fatigue criteria. These set of proposed formulae and methods allows us to assess the behaviour of a structural system from earthquakes.
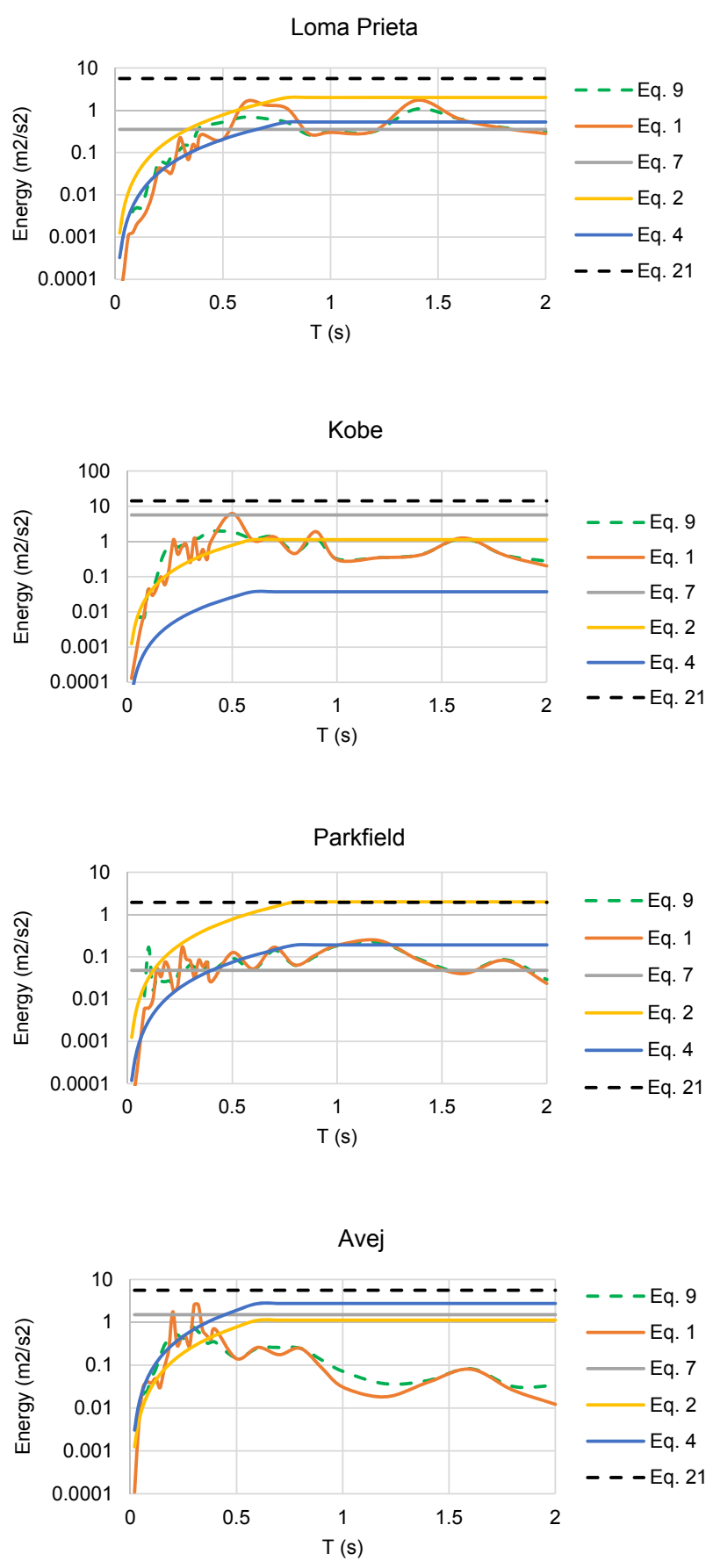

Figure 7. Seismic input energy into various systems from earthquake excitation based on different proposals 
Table 3

Cyclic deformation of elastoplastic system with single degree of freedom

\begin{tabular}{|c|c|c|c|c|}
\hline No. & Accelerogram & $\begin{array}{c}\sqrt{\tilde{t} S E D} \\
(\mathrm{~m})\end{array}$ & $\frac{h}{l^{2}}(\eta+2) \sqrt{\overline{t S E D}}$ & $\varepsilon_{B}$ \\
\hline 1 & Chi-Chi & 8.049 & 1.839 & \multirow{10}{*}{0.2} \\
\hline 2 & Friuli & 0.326 & 0.074 & \\
\hline 3 & Kobe & 1.259 & 0.288 & \\
\hline 4 & Kocaeli & 1.810 & 0.414 & \\
\hline 5 & Northridge & 1.827 & 0.417 & \\
\hline 6 & Ano Liosia_K & 0.174 & 0.040 & \\
\hline 7 & Ano Liosia_S & 0.153 & 0.035 & \\
\hline 8 & Avej & 0.385 & 0.088 & \\
\hline 9 & Kozani & 0.179 & 0.041 & \\
\hline 10 & Montenegro & 0.441 & 0.101 & \\
\hline
\end{tabular}

\section{Recommendations}

This research has shown that wide application of the energy method to the analysis of earthquake resistance of structures requires further development. First, it concerns the development of other (beyond the suggested) a unified approach for assessment seismic input energy and secondly, methods of distribution of seismic energy among elements of the structure (building).

The method and procedure proposed in this research work is recommended at initial stage of design, thus avoiding the consideration of numerous non-functional options of load-bearing structures.

Further development of the topic should be aimed at establishing a unified procedure for estimating seismic input energy and method of distribution of input energy among the various structural elements (building).

\section{References}

Advanced structural concepts (2008). NONLIN - A computer program for nonlinear dynamic time-history analysis of single and multi-degree of freedom systems.

Akiyama, H. (1985). Earthquake-resistant limit-state design for buildings. Tokyo: University of Tokyo Press.

Ambraseys, N.N, Douglas, J. (2003). Near-field horizontal and vertical earthquake ground motions. Soil Dynamics and Earthquake Engineering, 23, pp.1-18.

Amiri, G.G., Darzi, G.A, Amiri, J.V. (2008). Design elastic input energy spectra based on Iranian earthquakes. Canadian Journal of Civil Engineering, 35(6), pp. 635-646.

Anderson, J.C., Bertero, V.V. (2006). Use of Energy Concepts in Earthquake Engineering: A Historical Review. In Proceedings of the 8th National Conference on Earthquake Engineering, San Francisco.

Benavent-Climent, A, Pujades, L.G., Lopez-Almansa, F. (2002). Design energy input spectra for moderate seismicity regions. Earthquake Engineering and Structural Dynamics, 31, pp. 1151-1172.

Benavent-Climent, A., Zahran, R. (2010). An energy-based procedure for assessment of seismic capacity of existing frames: Application to RC wide beam systems in Spain. Earthquake Engineering and Structural Dynamics, 30, pp. 354-367.

Benavent-Climent. A. (2007). An energy-based damage model for seismic response of steel structures. Earthquake Engineering and Structural Dynamics, 36, pp. 1049-1064.

Berg, G.V., Thomaides, S.S. (1960). Energy consumption by structures in strong- motion earthquakes. In Proceedings of the second world conference on earthquake engineering, vol. 2, pp. 681-697.

Chai, Y.H. (2004). Incorporating low-cycle fatigue model into duration-dependent inelastic design spectra. Earthquake Engineering and Structural Dynamics, 34, pp. 83-96.

Chai. Y.H. (1995). Energy-based linear damage model for high-intensity seismic loading. Journal of Structural Engineering, 121(5), pp. 857-863.

Chou, C.C, Uang, C.M. (2000). Establishing absorbed energy spectra - an attenuation approach. Earthquake Engineering and Structural Dynamics, 29, pp. 1441-1455.

Decanini LD, Mollaioli F. (2001). An energy-based methodology for the seismic assessment of seismic demand. Soil Dynamics and Earthquake Engineering, 21, pp.113-137.

Decanini, L, Mollaoli, F. (1998). Formulation of Elastic Earthquake Input Energy Spectra. Earthquake Engineering and Structural Dynamics, 27, pp. 1503-1522.

Duma, G. (red.) (1995). Observations and lessons learned from the earthquake of the 12th December 1990 in southeast Sicily. In: Proceedings of the 10th european conference on earthquake engineering and structural dynamics, Vienna: Balkema. 
Erberik, A, Sucuoglu, H. (2004). Seismic energy dissipation in deteriorating systems through low cycle fatigue. Earthquake Engineering and Structural Dynamics, 33, pp. 49-67.

Fajfar, P, Vidic, T. (1994). Consistent inelastic design spectra: hysteretic and input energy. Earthquake Engineering and Structural Dynamics, 23, pp. 523-537.

Fajfar, P. (1992). Equivalent ductility factors taking into account low-cycle fatigue. Earthquake Engineering and Structural Dynamics, 21, pp. 837-848.

Fajfar, P., Vidic, T., Fischinger, M. (1992). On energy demand and supply in SDOF systems. In: proceedings of the nonlinear seismic analysis and design of reinforced concrete buildings. Amsterdam: Elsevier, pp. 41-61.

Hall, W.G. (1977). The capacity of extreme earthquake motions to damage structures. In Structural and Geotechnical Mechanics, a Volume Honoring Nathan M. Newmark. Prentice Hall, USA, pp.102-116.

Housner, G.W. (1956). Limit design of structures to resist earthquakes. In proceedings of the first World Conference on Earthquake Engineering. Berkeley, California, pp. 1-12.

Ing+ (2006). Sovryemyenniy komplyeks programm dlya proyektirovaniya stroityel'nih konstrooktsiy [Modern complex of programs for structural design]. Available at: http://www.tech-soft.ru. (Accessed on: 12.10.2016) (in Russian)

Kato, B., Akiyama, H. (1975). Energy input and damages in structures subjected to severe earthquakes. Journal of Structural and Construction Engineering, 235, pp. 9-18. (in Japanese)

Khashaee, P. et al. (2003). Distribution of Earthquake Input Energy in Structures. NISTIR 6903. Gaithersburg: Building and Fire Research Laboratory National Institute of Standards and Technology Gaithersburg.

Krawinkler. H. (1998). Pros and cons of a pushover analysis of seismic performance evaluation. Engineering Structures, 20, pp. 452-464.

Kuwamura, H., Galambos, T.V. (1989). Earthquake load for structural reliability. Journal of Structural Engineering ASCE, 115(6), pp.1446-1462.

McCabe, S.L., Hall, W.J. (1989). Assessment of seismic structural damage. Journal of Structural Engineering, 115, pp. 2166-2183.

Priestley, M.J.N., Calvi, G.M., Kowalsky, M,J. (2007). Displacement-based seismic design of structures. IUSS Press.

Routman, Y.L. (1997). Pseudo rigidity method for solving the problem of limit equilibri-um of rigid-plastic constructions. University Weimar: IKM.

Rutman, Yu.L. (2012). Analiz nagroozhyennosti sooroozhyeniya na osnovye vyelichini enyergyetichyeskogo krityeriya intyensivnosti zyemlyetryasyeniya [Analysis of structure loading based on the magnitude of energy intensity criteria of earthquake]. Structural mechanics and calculation of structures, 2, pp. 61-63

Rutman, Yu.L., Shiwua, A.J. (2015). Otsyenka syeysmichyeskoy enyergii, postoopivshyey v ooproogoplastichyeskooyoo sistyemoo s odnoy styepyen'yoo svobodi [Evaluation of the seismic energy absorbed by elasto-plastic system with a single degree of freedom]. Vestnik grazhdanskikh ingenerov [Bulletin of Civil Engineers], 2(49), pp. 64-74. (in Russian)

Safac, E. (2000). Characterization of seismic hazard and structural response by energy flux. Soil Dynamics and Earthquake Engineering, 20, pp. 39-43.

Seismosoft (2013). SeismoSignal - A computer program for signal histories. Available at:www.seismosoft.com (accessed on: 12.10.2016)

Shiwua, .A.J. (2014). Analiz enyergyetichyeskih myetodov otsyenki syeysmichyeskoy enyergii, postoopivshyey v sistyemoo pri zyemlyetryasyenii [Analysis of energy methods for the evaluation of seismic energy absorbed by a system during earthquake]. Vestnik grazhdanskikh ingenerov [Bulletin of Civil Engineers], 6(47), pp. 96-103. (in Russian)

Simbort, S.E. (2012). Opredeleniye koeffitsiyenta reduktsii s uchetom dinamicheskikh kharakteristik seysmicheskikh vozdeystviy [Determination of the reduction coefficient taking into account dynamic characteristics of seismic effects]. Ph.D. thesis. St. Petersburg University of Architecture and Civil Engineering (in Russian)

Sucuoglu, H., Erberik, A. (2004). Energy-based hysteresis and damage for deteriorating systems. Earthquake Engineering and Structural Dynamics, 33, pp. 69-88.

Sucuoglu, H., Nurtug, A. (1995). Earthquake ground motion characteristics and seismic energy dissipation. Earthquake Engineering and Structural Dynamics, 24(9), pp. 1195-213.

Teran-Gilmore, A., Jirsa, J.O. (2005). A simple damage model for practical seismic design that accounts for low cycle fatigue. Earthquake Spectra, 21(3), pp. 803-832.

Teran-Gilmore, A., Jirsa, J.O. (2007). Energy demands for seismic design against low-cycle fatigue. Earthquake Engineering and Structural Dynamics, 36, pp. 383-404.

Uang, C.M., Bertero, V.V. (1990). Evaluation of seismic energy in structures. Earthquake Engineering and Structural Dynamics, 19(1), pp. 77-90.

Zahrah, T.F., Hall, W.J. (1984). Earthquake energy absorption in SDOF systems. Journal of Structural Engineering, 110, pp. 1757-1772.

Zhu, T.J., Tso, W.K. (1992). Design of torsionally unbalanced structural systems based on code provisions II: strength distribution. Earthquake Engineering \& Structural Dynamics, 21, pp. 629-44. 